\title{
Administração pública tupiniquim: reflexões a partir da Teoria N e da Teoria P de Guerreiro Ramos
}

\author{
Tupiniquim public administration: reflections from Guerreiro Ramos's N Theory and P \\ Theory
}

Elisa Zwick $^{1}$

Marília Paula dos Reis Teixeira (in memoriam) ${ }^{2}$

José Roberto Pereira ${ }^{3}$

Ana Alice Vilas Boas ${ }^{4}$

\begin{abstract}
Resumo
O objetivo deste ensaio teórico é promover uma reflexão acerca da administração pública brasileira contemporânea sob o enfoque da Teoria N e da Teoria P de Guerreiro Ramos. Após a recuperação dos pressupostos de cada abordagem proposta por Ramos, buscou-se alinhá-las a diferentes teorias de administração pública. A administração pública gerencial, conhecida no âmbito internacional como nova administração pública, foi introduzida no Brasil no governo Fernando Henrique Cardoso por meio da Reforma do Estado. Tal qual foi planejada, a administração pública gerencial caracteriza-se como Teoria N, uma vez que está imbricada pela força da estrutura e pela racionalidade instrumental. Todavia, por esbarrar em características culturais, tais como o autoritarismo, o personalismo e o coronelismo, esse modelo não foi plenamente desenvolvido no Brasil, sendo relativizado em sua aplicação prática. Assim, tornou-se uma hibridização de diversos modelos de gestão, unindo características do patrimonialismo, da burocracia e do gerencialismo, bem como indícios de gestão social. Essa hibridização institui, na verdade, um novo modelo de gerir a coisa pública, formando o que se denomina administração pública tupiniquim, que se figura como uma administração pública flexibilizada, que absorve elementos de vários modelos e experiências ao longo da história no Brasil e no exterior. Desvendar os elementos que compõem a "administração pública tupiniquim" como uma verdadeira possibilidade objetiva alinhada à tipologia da Teoria $\mathrm{P}$ de Guerreiro Ramos é o que se busca mostrar neste ensaio teórico.
\end{abstract}

Palavras-chave: Teoria N. Teoria P. Possibilidade objetiva. Administração pública.

\section{Abstract}

The aim of this theoretical essay is to promote a reflection on the contemporary Brazilian public administration under the view of Guerreiro Ramos's N Theory and P Theory. After reviewing the assumptions of each approach proposed by

\footnotetext{
${ }^{1}$ Doutoranda em Administração pela Universidade Federal de Lavras (UFLA); Professora assistente da Universidade Federal de Alfenas (Unifal). Endereço: Unifal - Rua Celina Ferreira Otoni, 4000 - Padre Vítor, CEP 37048-395, Varginha-MG, Brasil. E-mail: elisazw@hotmail.com; elisa.zwick@unifal-mg.edu.br

${ }^{2}$ Doutoranda em Administração pela Universidade Federal de Lavras (UFLA). Endereço: Rua Rosina Silva Terra, n. 169, B. Fábricas, CEP 36301-220, São João Del Rei-MG, Brasil. E-mail: marilia0203@yahoo.com.br (in memoriam).

${ }^{3}$ Doutor em Sociologia pela Universidade de Brasília (UnB); Professor Associado III da Universidade Federal de Lavras (UFLA); Diretor de Contratos e Convênios - DICON; Coordenador da Incubacoop-UFLA. Endereço: Universidade Federal de Lavras, Prédio das PróReitorias, CEP 37200-000, Lavras - MG, Brasil. E-mail: jrobpereira25@yahoo.com.br; jpereira@dicon.ufla.br

${ }^{4}$ Doutora em Administração pela Universidade de Reading - Inglaterra; PhD em Administração pela Universidade de Reading - UK; Professora Associada I da Universidade Federal de Lavras (UFLA). Endereço: Via San Paolino, n. 35. Condomínio Província Di Lucca, Parque Belvedere, CEP 37200-000, Lavras - MG, Brasil. E-mail: ana.alice@dae.ufla.br
} 
Ramos, there was an attempt to align them to different contemporary theories of public administration. The managerialism, internationally known as new public management, was introduced in Brazil in the Fernando Henrique Cardoso government through the State Reform. Just as it was planned, the managerialism is characterized as $\mathrm{N}$ Theory, since it is embedded by structure force and instrumental rationality. However, by bumping into cultural features, such as authoritarianism, personalism, and "coronelismo", this model was not fully developed in Brazil, being relativized in its practical application. Thus, it became a hybridization of several management models, combining features of patrimonialism, bureaucracy, and managerialism, as well as evidence of social management. This hybridization establishes, in fact, a new model of managing public affairs, forming what is called Tupiniquim public administration, which figures itself as a flexible public administration, absorbing elements from many models and experiences throughout history in Brazil and abroad. Unveiling the elements of the "Tupiniquim public administration" as an actual objective possibility aligned to Guerreiro Ramos's P Theory is the aim of this theoretical essay.

Keywords: N Theory. P Theory. Objective possibility. Public administration.

\section{Introdução}

A corrente dominante na literatura em administração e em grande parte das ciências sociais preconiza que os países localizados no Hemisfério Norte são tidos como modelos ideais de desenvolvimento, cuja posição de destaque nos cenários econômico e social globais situa-se em um campo intocável. Sob a égide dessa concepção, os países cunhados sob o termo "subdesenvolvido", localizados no Hemisfério Sul, são condicionados à replicação dos modelos de decisão dos países chamados "desenvolvidos", com o intuito de alcançar os mesmos resultados destes. Essa mimese, que tem sido reproduzida já por algumas décadas na esfera do business, também se evidencia no âmbito da administração pública.

Especificamente no Brasil, observa-se que a importação do modelo da nova administração pública (NAP) carrega peculiaridades típicas das empresas privadas, sendo utilizado sem que se tenha empreendido uma leitura crítica sobre esse processo de implementação por parte dos proponentes. Isso pode ser explicado, em parte, pelo fato de o Brasil ter sido um país colonizado, no qual se formou uma cultura de aceitação passiva do estrangeiro. A herança da colonização imbrica uma fragilização que possibilita ainda a manutenção de uma dominação colonial, provinda da hegemonia dos padrões dos países de "Primeiro Mundo", "com sua pretensão de universalidade e de produção da verdade” (MISOCZKY, 2006, p. 4). Destarte, para se alcançar esse modelo, tido como ideal, abre-se caminho para a busca desenfreada pelo desenvolvimento. Heidemann (2009) esclarece que esse desenvolvimento, ditado pelos países de Primeiro Mundo, tem sido visto apenas como sinônimo de bons indicadores econômicos, negligenciando, assim, a esfera da evolução social.

Sob esses aspectos, tem-se que a era inaugurada pelo governo de Fernando Henrique Cardoso no Brasil, com a Reforma Administrativa do Estado em 1995, é um exemplo dessa busca pelo desenvolvimento estritamente econômico, ao aspirar, fundamentalmente, as dimensões produtivas. Assim, com a redefinição do papel do Estado, a década de 1990, é marcada como a época em que se visou a alterar profundamente os caminhos políticos na administração pública brasileira. As práticas gerencialistas passaram a preconizar, em essência, "a introdução e a aplicação dos princípios e das técnicas de administração por resultados no setor público com base na flexibilização da burocracia" (PEREIRA, 2010, p. 113), as quais foram amplamente empregadas na tentativa de solucionar a crise dos anos anteriores e, principalmente, por se tratar de um modelo de administração considerado bem-sucedido em países do Hemisfério Norte, fundando-se, assim, a administração pública gerencial no Brasil.

Todavia, esse modelo de gestão não teve consolidado um ideal de nova cultura política como propugnava Cardoso (2003), tendo em vista que o cenário da administração pública brasileira é permeado por características de diferentes momentos históricos, dada a diversidade cultural e a extensão territorial do Brasil. Como compreende Freitas Jr. (2009), as peculiaridades da gestão pública brasileira acompanham a evolução do Estado, identificado na maior parte das vezes com a pessoa do governante, sendo-lhe inerente o 
personalismo e o patrimonialismo, bem como condutas semelhantes ao coronelismo, ao clientelismo e ao autoritarismo. A burocracia surgiu, então, para racionalizar os processos e combater essas práticas. Mais tarde, para sanar as discrepâncias da burocracia, pensou-se ser o gerencialismo o modelo que iria "salvar a pátria".

Tendo em vista a singularidade brasileira, defendemos neste ensaio teórico que a proposta gerencialista foi tropicalizada em função de suas particularidades, transformando-se em uma "administração pública tupiniquim", uma vez que há uma hibridização das propostas patrimonialista, burocrática, gerencial e social, sendo estas somadas às demais características existentes na realidade do país, de modo a se formar uma configuração de gestão tipicamente brasileira.

A fim de auxiliar na interpretação dos meandros dessa hibridização, remetemo-nos a Guerreiro Ramos, autor que em seu estudo a respeito das Teorias $\mathrm{N}$ e $\mathrm{P}$ abre novos caminhos teóricos para pensar e compreender a modernidade enquanto um dos principais tópicos contemporâneos, pois passa a delinear um arcabouço teórico que subsidia a análise da dualidade entre a força determinista dos modelos dos países de Primeiro Mundo e um paradigma emergente, cuja essência é a noção de possibilidade. As Teorias N e P de Guerreiro Ramos (2009) se remetem, respectivamente, a essa dicotomia entre estrutura e ação. Unindo-se a essas teorizações e a presente constatação de que há uma importação ingênua e acrítica dos conteúdos de países ditos desenvolvidos à realidade brasileira é preciso melhor entender quais são os fundamentos teóricos desses conteúdos que caracterizam a administração pública brasileira contemporânea.

Desse modo, tem-se como objetivo geral deste ensaio teórico promover uma reflexão crítica acerca da administração pública contemporânea brasileira sob o enfoque das Teorias N e P de Guerreiro Ramos. Especificamente, busca-se: (i) caracterizar a Teoria $\mathrm{N}$ e a Teoria $\mathrm{P}$, enquanto proposta teórico-metodológica; (ii) contextualizar a adoção do modelo gerencialista no Brasil como resultado da Reforma do Estado nos anos 1990; e (iii) apresentar proposições de alguns autores nacionais que permitam correlacionar os modelos de gestão pública desenvolvidos no Brasil com as Teorias N e P de Guerreiro Ramos.

Para alcançar esses objetivos, estruturou-se este ensaio em cinco partes, sendo a primeira esta introdução; a segunda, a caracterização das Teorias N e P como proposta teórico-metodológica; a terceira constitui-se em uma síntese teórica para se compreender os rumos da nova administração pública; a quarta busca trazer evidências da Teorias $\mathrm{N}$ e $\mathrm{P}$ na administração pública brasileira, de modo a adjetivá-la como tupiniquim; a quinta é composta pelas nossas considerações finais.

\section{Teoria N e Teoria P: Uma Proposta Teórico-Metodológica}

A ideia de inserir Guerreiro Ramos neste ensaio como principal autor que fundamenta uma proposta teóricometodológica para a análise da administração pública deriva do fato de que sua teorização é, declaradamente, direcionada não só às empresas privadas, mas, também, de modo especial, à administração pública e às ciências sociais em geral. Isso fica claro quando Ramos (1981) propõe "A nova ciência das organizações" e afirma, já no prefácio da obra, que esta é dirigida a problemas de ordenação dos negócios sociais e pessoais em termos de micro e macroperspectivas. Assim, o teórico refuta, desde o início de seus escritos, uma teoria das organizações centrada no mercado, argumentando que seus princípios, quando aplicados a todas as formas de atividade, dificultam a atualização de possíveis novos sistemas sociais, além de serem limitados ao terem promovido a desfiguração da vida humana. Ou seja, a ideologia do mercado, quando reina sobre todas as ações humanas e se torna um pressuposto básico, faz com que não se apercebam a extensão das possibilidades objetivas. 
Em vista disso, torna-se central, nesta análise, retomar o pano de fundo das proposições de Guerreiro Ramos (1996), em que o autor recupera a importância da superação do "reducionismo sociológico", o qual concebe a explicação dos fenômenos a partir de somente uma de suas partes. Seu texto "A modernização em nova perspectiva: em busca do modelo da possibilidade" (RAMOS, 2009) é pontual nesse sentido, por retomar a dualidade clássica entre a ação e a estrutura sob uma nova perspectiva de sua autoria: a Teoria da Necessidade (N) e a Teoria da Possibilidade (P). Assim, Guerreiro Ramos (2009) avança ao contextualizar as Teorias $\mathrm{N}$ e $\mathrm{P}$ por meio da conjectura da modernização e ao vislumbrar esse fenômeno e seus autores, passa a observar que podem ser situados em um continuum, cujos polos denominou Teoria $\mathrm{N}$ e Teoria $\mathrm{P}$.

Nesse cenário, destaca-se que a Teoria $\mathrm{N}$ fundamenta-se em autores que estão sob a égide do discurso da estrutura, ou seja, que defendem o domínio da estrutura sobre a ação individual e coletiva. Já a Teoria $\mathrm{P}$ abarca autores que preconizam o potencial da ação diante da força da estrutura, da emancipação do indivíduo. É fundamental destacar que essa discussão de Guerreiro Ramos acompanha também a dicotomia entre a racionalidade instrumental e a racionalidade substantiva, uma vez que os teóricos estruturalistas têm maior inclinação para a primeira e as teorizações dos propugnadores da ação para a segunda. Em análise dessa proposta de Guerreiro Ramos, Rezende (2009) enfatiza que, em função de outro tipo de reducionismo, o epistemológico, o qual evidencia uma distorção do que é conhecer, a racionalidade instrumental limita as Ciências Sociais ao subordinar suas propostas teóricas, negligenciando a razão noética ou substantiva. Desse modo, sob o cogito cartesiano, ou melhor, pelo exercício da razão moderna calcada na instrumentalidade, as ações individuais e coletivas são resultado de razões estritamente funcionais. Rezende (2009) segue argumentando que Guerreiro Ramos alerta para o fato de que a tensão entre o "moderno" e o "não moderno" está condicionada a uma redução antropológica, que retrata o ser humano como sendo produto do cálculo utilitário de resultado e do seu autointeresse. Assim, o trabalho de Guerreiro Ramos visa a combater a tirania da inteligência reduzida ao instrumental.

A Teoria $\mathrm{N}$ preconiza que na realidade social histórica é possível identificar um curso de acontecimentos definidos, que é resultado da combinação de causas absolutamente necessárias. A partir disso, ao caracterizar a Teoria $\mathrm{N}$, especificamente no que tange à modernização, Guerreiro Ramos informa que esta tem como pressuposto a existência de uma lei de necessidade histórica que orienta as sociedades tidas como "em desenvolvimento" a alcançarem o estágio das então consideradas modernizadas. Sob essa lente de "nações desenvolvidas" versus "nações em desenvolvimento", os teóricos filiados à Teoria N categorizam outras dicotomias, como sociedades "paradigmáticas" versus sociedades "seguidoras". Ressalta-se que essas bifurcações são características da modernidade (BECK, GIDDENS e LASH, 1997). Destarte, essas categorias reiteram a existência de nações desenvolvidas e outras que devem aderir compulsoriamente aos pressupostos das que alcançaram a modernização. Guerreiro Ramos (2009) complementa ao assinalar que os "pré-requisitos da modernização" estão estritamente em função dos postulados determinísticos da Teoria N.

De outra parte, Guerreiro Ramos conceitua a Teoria P como sendo "uma concepção de realidade histórica e social que a vê como resultado permanente de uma tensão entre possibilidades objetivas e escolhas humanas" (RAMOS, 2009, p. 49). Destaca-se, aqui, que o conceito de "possibilidade objetiva" (SOARES, 2006, p. 26) utilizado por Guerreiro Ramos está fundamentado em Max Weber, o qual é reconhecidamente o pensador de sua maior influência. O combate enfático de Weber à ideia de que a ciência possa formular concepções de mundo de validade universal é que abre espaço ao conceito de possibilidade objetiva. Segundo Freund (1987, p. $55 ; 58)$,

A categoria de possibilidade objetiva situa sob outra forma o problema da imputação causal. Querer explicar um acontecimento histórico enquadrando-o sob uma lei geral é desvirtuar a História, que é formada de uma sucessão de acontecimentos singulares [...] a um conjunto singular que Weber denomina de constelação. [...] A possibilidade objetiva constrói um "quadro imaginário", uma utopia [...], ela faz abstração, pelo pensamento, de um ou vários elementos da realidade, para indagar o que teria podido acontecer no caso considerado (grifos da autora). 
Weber, como reitera Ramos (2009), progrediu em suas reflexões cunhando o conceito de "possibilidade objetiva" enquanto passível de ser real e existente, servindo como ferramenta analítica de exame sociológico. De forma oposta aos pressupostos fatalísticos da Teoria $\mathrm{N}$, a Teoria $\mathrm{P}$ assume os desígnios dessa "possibilidade objetiva" de Max Weber e apresenta como fundamentos principais: (i) a concepção de que a modernidade não se figura, a rigor, em uma região do mundo e que esse processo de modernização não tem que se orientar em um arquétipo platônico; e (ii) todas as nações, sem exceção, sempre terão alternativas próprias de modernização, todavia, sua efetivação pode ser sobreposta por um modelo normativo rígido. Nesse ponto, qualquer semelhança na inflexão desse pensamento com o tríplice sentido da "redução sociológica" de Guerreiro Ramos não é mera coincidência, pois, como já foi dito, em muito o pensamento desse autor foi influenciado pela leitura de Weber.

Guerreiro Ramos assinala que a evolução das Ciências Sociais depende da sistematização de um paradigma emergente, que, para ele, está fundamentalmente atrelado à noção de "possibilidade". Nesse sentido, para o referido autor, o conceito weberiano de "possibilidade" constitui-se como requisito indispensável para o estudo científico da realidade social. Todavia, a Teoria $\mathrm{P}$, por sua vez, não é sinônimo de enfoque indeterminista, haja vista que a liberdade é sempre limitada, uma vez que "escolher uma possibilidade em determinada situação é escolher dentro de certos limites" (RAMOS, 2009, p. 46). Unindo-se a essas ideias não se pode deixar de se referir a Ernst Bloch como um dos expoentes do pensamento que procura abrir novos caminhos para a dialética, distanciando-se de reduções mecanicistas.

Ao comentar Bloch, Nascimento (2008, p. 37) traz para o esclarecimento das "possibilidades objetivas" duas formas de utopia (a abstrata e a concreta), destacadas por Bloch, cuja segunda, a utopia concreta, interessa comentar. A utopia concreta estabelece que, enquanto antecipa um "dever-ser" que "ainda-não-é", ela faz parte da realidade, "é imanente ao movimento social", e é visão subjetiva de uma mobilização real, de uma transformação real do mundo. Para Bloch (2005; 2006a; 2006b), a utopia manifesta um poder crítico diante da realidade, sendo, nesse sentido, a história humana um oceano de possibilidades sempre abertas. Outra passagem do autor é emblemática nesse sentido: "há ainda algo em aberto, que pode ser concebido diferentemente do que até agora, que pode ter suas medidas invertidas, pode ser amarrado de modo diferente, pode ser alterado" (BLOCH, 2005, p. 221).

Diante dessas reflexões, torna-se pertinente expor em maiores detalhes (Quadro 1) a análise das premissas da Teoria N e da Teoria P, pensadas por Guerreiro Ramos, as quais se expressam nitidamente como ideologicamente opostas, uma vez que a primeira assume as características do one best way e a segunda visa a promover o rompimento da estrutura.

Quadro 1

Teoria $\mathbf{N}$ versus Teoria $\mathbf{P}$

\begin{tabular}{|c|c|}
\hline Teoria $\mathbf{N}$ & Teoria P \\
\hline $\begin{array}{l}\text { 1. Tudo o que aconteceu é a única coisa que poderia } \\
\text { ter acontecido. }\end{array}$ & $\begin{array}{l}\text { 1. Tudo o que aconteceu é uma entre as muitas } \\
\text { possibilidades objetivas que poderiam ter } \\
\text { acontecido. }\end{array}$ \\
\hline $\begin{array}{l}\text { 2. O curso dos acontecimentos resulta da ação } \\
\text { recíproca de causas absolutamente necessárias. } \\
\text { Uma mente onisciente, que conhece todas essas } \\
\text { causas necessárias, poderia prever, com absoluta } \\
\text { certeza, o que terá de acontecer a curto e longo } \\
\text { prazos. Presume-se como possível o } \\
\text { conhecimento sinóptico do processo social. }\end{array}$ & $\begin{array}{l}\text { 2. Nenhum curso de acontecimentos pode ser } \\
\text { considerado resultante da ação recíproca de } \\
\text { causas absolutamente necessárias. O curso dos } \\
\text { acontecimentos resulta continuamente do jogo } \\
\text { entre fatores objetivos e opções humanas. Assim, } \\
\text { é possível fazer previsões, mas apenas com graus } \\
\text { variáveis de certeza, dependendo sempre das }\end{array}$ \\
\hline
\end{tabular}




\begin{tabular}{|c|c|}
\hline & $\begin{array}{l}\text { circunstâncias concretas. Jamais poder-se-ia } \\
\text { chegar a um conhecimento sinóptico do processo } \\
\text { social. }\end{array}$ \\
\hline $\begin{array}{l}\text { 3. O que faz o homem pensar em possibilidades é } \\
\text { sua ignorância ou seu conhecimento incompleto } \\
\text { do curso dos acontecimentos necessários. Existem } \\
\text { apenas possibilidades epistêmicas ou lógicas. }\end{array}$ & $\begin{array}{l}\text { 3. As possibilidades podem ser reais e } \\
\text { empiricamente demonstradas. A possibilidade } \\
\text { objetiva opõe-se à possibilidade abstrata, eis que } \\
\text { se relaciona necessariamente com uma situação } \\
\text { dada; esta possibilidade pode se realizar. }\end{array}$ \\
\hline $\begin{array}{l}\text { 4. Existe um processo normal e unilinear de } \\
\text { evolução, um caminho ótimo e único a ser } \\
\text { palmilhado rumo ao futuro. Se observarmos os } \\
\text { pré-requisitos, podemos evitar descaminhos e } \\
\text { colapsos. }\end{array}$ & $\begin{array}{l}\text { 4. Não existe processo normal unilinear. A história } \\
\text { sempre nos apresenta um horizonte aberto a } \\
\text { possibilidades múltiplas. A qualquer momento } \\
\text { podem ocorrer eventos inesperados, conduzindo } \\
\text { a sociedade a um novo estágio diferente da } \\
\text { imagem convencional de seu futuro. }\end{array}$ \\
\hline $\begin{array}{l}\text { 5. No que tange ao presente, a tarefa da ciência } \\
\text { social é mostrar o que, em última análise, irá } \\
\text { necessariamente acontecer e estabelecer os pré- } \\
\text { requisitos para sua realização com base no que } \\
\text { aconteceu anteriormente. }\end{array}$ & $\begin{array}{l}\text { 5. No que respeita ao presente, a tarefa da ciência } \\
\text { social é descobrir o horizonte de suas } \\
\text { possibilidades, a fim de contribuir para a } \\
\text { participação humana na construção e para a } \\
\text { transformação consciente das sociedades } \\
\text { contemporâneas. }\end{array}$ \\
\hline $\begin{array}{l}\text { 6. É pernicioso ao cientista social ser protagonista no } \\
\text { processo social. Ele deve ser um espectador, um } \\
\text { observador afastado da arena dos interesses, a } \\
\text { fim de ser capaz de ver, sem ideias preconcebidas, } \\
\text { a orientação ao rumo transcendente do processo. }\end{array}$ & $\begin{array}{l}\text { 6. Sem ser protagonista no processo social não se } \\
\text { pode ser integralmente um cientista social. A ideia } \\
\text { de um pensar separado da prática é uma } \\
\text { contradição de termos. Não há pensar sem um } \\
\text { rudimento de prática, nem há prática sem um } \\
\text { rudimento de teoria. }\end{array}$ \\
\hline $\begin{array}{l}\text { 7. Na história contemporânea, devemos distinguir } \\
\text { sociedades em desenvolvimento. As primeiras, } \\
\text { como sociedades paradigmáticas, exibem às } \\
\text { subdesenvolvidas a imagem do futuro destas. } \\
\text { Deve-se elaborar indicadores de desenvolvimento } \\
\text { ou modernização, para que os agentes } \\
\text { incumbidos do aprimoramento das condições nas } \\
\text { sociedades em desenvolvimento possam orientar- } \\
\text { se quanto à melhor maneira de alcançar a } \\
\text { modernização ou o desenvolvimento. }\end{array}$ & $\begin{array}{l}\text { 7. No momento atual da história, a dicotomia entre } \\
\text { sociedades desenvolvidas é teoricamente } \\
\text { desnorteadora. Na realidade, a categoria cardinal } \\
\text { das ciências sociais é o mundo, que hoje possui as } \\
\text { características de um sistema. Sob a ótica desse } \\
\text { sistema, todas as sociedades estão em } \\
\text { desenvolvimento. Todas elas são, em diferentes } \\
\text { graus, ao mesmo tempo atrasadas e modernas. Só } \\
\text { podem existir indicadores ad hoc de } \\
\text { modernização, e sua natureza e relação só fazem } \\
\text { sentido quando estão associadas a possibilidades } \\
\text { de desenvolvimento ou modernização de cada } \\
\text { sociedade. }\end{array}$ \\
\hline
\end{tabular}

Fonte: Ramos (2009, p. 54-55).

Com relação ao discurso de desenvolvimento, a Teoria $\mathrm{P}$ passa a compreender as ideias de autores que rompem com a bifurcação entre as conceituações de nações "desenvolvidas" e "em desenvolvimento" ao defender que todas as sociedades se encontram em um estágio "em desenvolvimento", visto que são permeadas, concomitantemente, pelo atraso e pela modernização. Portanto, Guerreiro Ramos conceitua como 
inautêntico o discurso de diferenciação entre sociedades de Primeiro Mundo e outras de Terceiro Mundo, defendida pelos pressupostos da Teoria $\mathrm{N}$, pois isso constitui uma ficção social. As distinções entre a Teoria $\mathrm{N}$ e a Teoria $\mathrm{P}$ permitem também a identificação da inclinação de autores para uma ou outra vertente. Todavia, cabe uma análise criteriosa quanto a isso, uma vez que Ramos (2009) alerta que os cientistas sociais contemporâneos que defendem a força da estrutura não se intitulam explicitamente como orientados pelos pressupostos da Teoria N.

Para deixar mais claro o quanto a racionalidade formal está relacionada com os pressupostos da Teoria N, reproduzimos o quadro da teoria da vida humana associada (Quadro 2), formulado por Guerreiro Ramos, o qual evidencia também o quanto a racionalidade substantiva corrobora mais diretamente com a Teoria P.

Quadro 2

Teoria da vida humana associada

\begin{tabular}{|c|c|c|c|}
\hline \multicolumn{2}{|r|}{ Formal } & \multicolumn{2}{|r|}{ Substantiva } \\
\hline I. & $\begin{array}{l}\text { Os critérios para ordenação das ações } \\
\text { humanas são dados socialmente. }\end{array}$ & I. & $\begin{array}{l}\text { Os critérios para ordenação das ações } \\
\text { humanas são racionais, isto é, evidentes por si } \\
\text { mesmos ao senso comum individual, } \\
\text { independentemente de qualquer processo } \\
\text { particular de socialização. }\end{array}$ \\
\hline II. & $\begin{array}{l}\text { Uma condição fundamental da ordem } \\
\text { social é que a economia se transforme } \\
\text { num sistema autorregulado. }\end{array}$ & II. & $\begin{array}{l}\text { Uma condição fundamental da ordem social é } \\
\text { a regulamentação política da economia. }\end{array}$ \\
\hline III. & $\begin{array}{l}\text { O estudo científico das associações } \\
\text { humanas é livre do conceito de valor: } \\
\text { há uma dicotomia entre valores e fatos. }\end{array}$ & III. & $\begin{array}{l}\text { O estudo científico das associações humanas é } \\
\text { normativo: a dicotomia entre valores e fatos é } \\
\text { falsa, na prática, e, em teoria, tende a produzir } \\
\text { uma análise defectiva. }\end{array}$ \\
\hline IV. & $\begin{array}{l}\text { O sentido da história pode ser captado } \\
\text { pelo conhecimento, que se revela } \\
\text { através de uma série de determinados } \\
\text { estados empírico-temporais. }\end{array}$ & IV. & $\begin{array}{l}\text { A história torna-se significante para o homem } \\
\text { através do método paradigmático de } \\
\text { autointerpretação da comunidade organizada. } \\
\text { Seu sentido não pode ser captado por } \\
\text { categorias serialistas de pensamento. }\end{array}$ \\
\hline V. & $\begin{array}{l}\text { A ciência natural fornece o paradigma } \\
\text { teórico para a correta focalização de } \\
\text { todos os assuntos e questões } \\
\text { suscitados pela realidade. }\end{array}$ & V. & $\begin{array}{l}\text { O estudo científico adequado das associações } \\
\text { humanas é um tipo de investigação em si } \\
\text { mesmo, distinto da ciência dos fenômenos } \\
\text { naturais, e mais abrangente que esta. }\end{array}$ \\
\hline
\end{tabular}

Fonte: Ramos (1984, p. 29).

Assim, as Teorias P e N de Guerreiro Ramos podem ser utilizadas como uma poderosa ferramenta analítica dos caminhos seguidos pelos autores que nortearam os rumos da administração pública contemporânea. É possível identificar, claramente, as tendências teóricas em direção a uma postura instrumental e estrutural ou substantiva da ação, sendo que essa apreensão de sentidos ideológicos é requisito fundamental para se compreender as "entranhas" de algumas obras que definiram, em muito, condutas administrativas adotadas no Brasil. 
Contudo, deve-se proceder a uma análise que seja extremamente criteriosa e que considere o contexto macro da realidade na qual estão inseridos esses autores no momento de confecção de suas obras. Assim, por meio do arcabouço proposto por Guerreiro Ramos e das cautelas ao se utilizar as Teorias $\mathrm{N}$ e $\mathrm{P}$ como uma proposta teórico-metodológica, será apresentado, a seguir, o contexto histórico de desenvolvimento da administração pública gerencial.

\section{Contexto Histórico da Administração Pública Gerencial}

Para Pereira (2010), quando se busca a compreensão das ações governamentais, deve-se, primeiramente, investigar sob qual enfoque está calcada a tipologia predominante de Estado, visto que ela é definidora do tipo de configuração que assume a administração pública de um país. Segundo Paes de Paula (2005a), o entendimento dessa relação abarca as dimensões Econômico-Financeira, Institucional-Administrativa e Sociopolítica. Nesse sentido, busca-se descrever o contexto histórico e os aspectos teóricos relevantes do pensamento da administração pública gerencial nos anos 1990, os quais contribuíram para a adoção da administração pública gerencial no Brasil.

Ao situar, historicamente, o gerencialismo, observa-se que sua origem está relacionada à frustração do welfare state nas décadas de 1970 na Inglaterra e de 1980 nos Estados Unidos. O primeiro país teve como figura importante nesse processo a atuação de Margareth Thatcher, que propunha um modelo de gestão do Estado calcado na descentralização administrativa, na privatização e na terceirização dos serviços públicos. Já nos Estados Unidos, a revolução intelectual conservadora deu-se com a eleição de Ronald Reagan, que manteve as políticas de implementação de políticas monetaristas anti-inflacionárias do presidente anterior, aliando-se, também, ao tripé thatcherista de gestão do Estado (PAES DE PAULA, 2005a). Esses movimentos, em ambos os países, tiveram forte apoio intelectual dos think tanks, centros de pensamento de bases ideológicas neoconservadoras.

Mediante a tese do enxugamento da máquina do Estado, os governos, em especial o dos Estados Unidos da América (EUA), passaram a focar a lógica do empreendedorismo como a tábua de salvação para o alcance da otimização dos serviços do Estado. Isso implicou uma luta contra o modelo burocrático clássico de administração pública, mediante a intensa aplicação dos princípios da administração por objetivos, que consistem em técnicas importadas do modo de gerir da empresa privada. Uma das obras que cabe analisar para compreender esse processo de transição para o gerencialismo, entendido no Brasil como administração pública gerencial, é "Reinventando o governo" (OSBORNE e GAEBLER, 1994). Centrado na descrição de novos meios de como o governo americano passou a funcionar nos níveis federal, estadual e local, o livro tornou-se um best-seller internacional, em grande parte por pregar o ideal da eficiência e exemplos de sucesso na administração pública. Isso fica claro quando os autores propõem a superação da crise oriunda do fracassado do welfare state com a adoção de um "receituário infalível" que elevasse as ações governamentais a outro patamar, com base na ideologia neoliberal.

Claramente orientado pela racionalidade instrumental das empresas privadas, o governo deveria ser pautado pela visão empreendedora, a partir da qual se soubesse fazer mais com menos recursos, estabelecendo parcerias com outros setores e tratando o cidadão como cliente. Osborne e Gaebler (1994) descrevem com grande riqueza de detalhes o sucesso da administração gerencial em vários estados norte-americanos, procurando convencer o leitor de que os rumos adotados foram os mais adequados para a gestão pública naquela nação, constituindo-se como um "tipo ideal”, que pode ser adotado por outros países.

Assim, esse "receituário", considerado pelos autores acima como um novo paradigma de administração pública no cenário mundial, caracteriza-se pela adoção, na gestão pública, de práticas comuns no gerenciamento de empresas privadas. Outro aspecto importante de "Reinventando o governo" é que Osborne e Gaebler (1994) atribuem ao novo modo de gestão dos Estados Unidos significados de caráter progressista, 
como a excelência, a renovação, o empreendedorismo e a modernização (PAES DE PAULA, 2005a). A valorização da cultura do management no cenário da administração pública, com vistas a replicá-lo, motivou um amplo movimento mundial nessa direção, inclusive na política brasileira adotada pelo governo de Fernando Henrique Cardoso.

Por outro lado, o gerencialismo se fundamenta, também, nos escritos de Antony Giddens, em especial "A terceira via" (GIDDENS, 1999) e "A terceira via e seus críticos" (GIDDENS, 2001), em que o autor propõe uma reestruturação do welfare state. As ideias de Giddens somam força às orientações prescritivas de Osborne e Gaebler (1994), na medida em que fundamentam o "novo progressismo" adotado pelo ministro Tony Blair no governo britânico, bem como por Bill Clinton nos Estados Unidos e por outros governos, como o Brasil, a Alemanha, a França, a Itália e o México.

Segundo Giddens (1999), a terceira via se fundamenta nas ideias do socialismo e do liberalismo. Enquanto o socialismo clássico prevê a igualdade absoluta para todos, por outro lado, o liberalismo defende o fundamentalismo de mercado. A proposta de Giddens, da terceira via, é o aproveitamento do que há de melhor nessas doutrinas. Assim, constitui-se em uma ideologia social-democrata moderna e, ao mesmo tempo, um programa de "governos progressistas".

Segundo Paes de Paula (2005a, p. 77), a política de terceira via sofistica o discurso do livre mercado e o adapta ao ideário da globalização, não descartando reformas neoconservadoras, de inspiração liberal e "progressista". Assim, a autora destaca que a nova administração pública ganha novas nuanças e se consolida como um novo modelo para a gestão pública contemporânea, que se tornou referência nos governos "socialliberais".

Giddens recebe críticas à sua proposta, tais como: de ser um projeto amorfo, impreciso, que cai no conservadorismo ao adotar a estrutura básica do neoliberalismo, em que não existem critérios de redistribuição e, uma vez sendo assim, não passa da retomada precária do welfare state, por suprimir uma série de direitos. Ainda, além de permitir que o mercado dite as regras e exalte a propriedade privada, a terceira via é criticada como indiferente a questões ecológicas, como o próprio Giddens (2001) apresenta em seu texto.

Entretanto, a exemplo do que fora inaugurado por Rousseau, Giddens (1999) passa a pautar-se pela construção de um novo contrato social, em que o governo, a economia e as comunidades devem convergir para o interesse da solidariedade e da justiça social. Com isso, fomentaria uma sociedade diversificada baseada em princípios igualitários, em que inclui, também, a globalização como tema central nesse processo. Giddens (2001) propõe, resumidamente, a ideia de "democratizar a democracia", num movimento em que se possam instaurar virtudes cívicas e sustentar os fundamentos morais da sociedade, o que para ele não se constitui em uma retomada do neoliberalismo, mas revela que o governo tem papel importante nesse novo contrato social, uma vez que se une a ele o mercado e a sociedade. O mercado tem, aqui, o papel de contribuir para a cidadania e reduzir a desigualdade.

Em síntese, verifica-se que tanto Osborne e Gaebler (1994) quanto Giddens (1999; 2001), procuram mostrar as vantagens da adoção das práticas gerencialistas no setor público. Esse modelo foi replicado em diversas nações, estendendo-se, em especial, também à Austrália e à Nova Zelândia. No Brasil, o modelo foi introduzido pelo ministro Luiz Carlos Bresser-Pereira, principal pensador da reforma empreendida pelo Ministério da Administração Federal e da Reforma do Estado (Mare).

\section{Administração Pública Tupiniquim: Uma Possibilidade Objetiva?}

Perfazendo um resgate histórico da gestão pública no Brasil, observa-se que o patrimonialismo, a burocracia e a administração pública gerencial foram os três principais modelos preponderantes ao longo do tempo. 
Filippim, Rossetto e Rossetto (2010) distinguem que o patrimonialismo, que prevaleceu no período do Brasil Colônia, Império e na República Velha, tem como principais características: a lealdade pessoal ao mandatário; o favoritismo, assistencialismo e clientelismo, que mantêm a população dependente de ações esporádicas; as práticas firmadas pela tradição e pontos de vista puramente pessoais, que caracterizam disfunções e vícios na administração pública; bem como o improviso pela predominância do poder doméstico na elaboração de decisões e alocação de recursos.

Com relação às características da burocracia, instaurada no período getulista, Filippim, Rossetto e Rossetto (2010) destacam que o modelo prima, essencialmente, pela especialização do serviço, eficiência, legalismo, foco nos controles, disciplina e impessoalidade. Esses dois modelos não foram adotados linearmente, visto que se desenvolveram, muitas vezes, ao longo da história, de modo concomitante, devido à dialeticidade do processo político e histórico (FILIPPIM, ROSSETTO e ROSSETTO, 2010).

Pelo fato de ser um país que foi colonizado, o Brasil constituiu uma propensão para a adoção de modelos estrangeiros. No que tange à administração pública, a introdução e o desenvolvimento do gerencialismo é um dos exemplos mais recentes de importação. Sua ampla divulgação e adoção no Brasil se justifica pelo argumento de autoridade que sustenta o gerencialismo como uma forma de gestão pública de sucesso em países que são tidos como de Primeiro Mundo, modernizados e desenvolvidos. O Consenso de Washington foi o estopim desse processo, pois possibilitou que se firmasse uma série de acordos internacionais, influenciando, intensamente, a transposição do modelo para o Brasil, formando, com isso, um "paradigma" de desenvolvimento a ser alcançado.

Assim, por forte influência dos relatórios do Consenso de Washington, a ideologia da terceira via e das práticas gerencialistas foi incorporada no âmbito brasileiro, movimento que teve sua essência retratada na obra organizada por Bresser-Pereira e Spink (2003), "Reforma do Estado e administração pública gerencial", cuja primeira edição é de 1998. Os organizadores trazem uma coletânea de textos que versam sobre os resultados de um seminário ocorrido em 1996, em Brasília, e que teve como pano de fundo a intenção de transição da administração pública brasileira burocrática para a gerencial. O livro é prefaciado por Fernando Henrique Cardoso (2003), presidente da República na ocasião, que defendia com veemência o gerencialismo como uma nova cultura pública a ser conquistada, pois é calcada na qualidade, na produtividade, nos resultados, na responsabilidade dos funcionários, entre outros aspectos. A administração pública de cunho gerencial foi, então, introduzida partindo do topo do governo em direção às bases, o que trouxe muitos questionamentos a respeito de sua legitimidade. No entanto, a Reforma do Estado buscou apelo no combate às características culturais depreciadoras da vida pública, tais como as disfunções burocráticas, 0 personalismo, o patrimonialismo ou rent-seeking (BRESSER-PEREIRA, 2003a). Bresser-Pereira (2003b) considera que a redefinição do papel do Estado e as implicações da reforma só são possíveis à medida que ocorrem mudanças na dimensão institucional-legal, cultural e da cogestão.

Przeworski (2003), por sua vez, analisa os tipos de relação entre "principals e agents" - regulação, supervisão e responsabilização - defendendo o maior controle do governo, corroborando a mesma ideia de Osborne e Gaebler (1994), quando falam de "navegar" ao invés de "remar" - perpetuando a necessidade de um Estado ágil. Kettl (2003) sustenta os princípios do Estado mínimo, argumentando ser esta uma tendência universal, já implementada em países desenvolvidos e, por isso, fadada ao sucesso. Além disso, está presente em seu discurso a aplicação da administração por objetivos, reforçando a busca por resultados e otimização das tarefas.

A discussão sobre a reforma do Estado se estende para a América Latina por meio de dois autores: Glade (2003) e Catalá (2003). O primeiro expõe a complementaridade entre a reestruturação econômica e a Reforma do Estado, primando por defender sua urgência na América Latina. A justificativa é de que três processos de mudança estão em curso: a democratização, a crescente liberalização e privatização e a necessidade de proteção social. Catalá (2003) apresenta os desafios e as oportunidades das democracias 
latino-americanas, salientando que há reformas pendentes quanto à adoção do gerencialismo e reconhece a necessidade de adaptações às condições específicas de cada país. Mediante a descrição das proposições de grande parte dos textos da obra, é possível concluir que a coletânea organizada por Bresser-Pereira e Spink (2003) é composta por escritos que resgatam o cenário internacional do gerencialismo, buscando reconhecêlo como prática de sucesso de países modernizados.

Ademais, vale analisar o enfoque da produção recente de Bresser-Pereira sobre esse quesito, visto que representa um dos principais propugnadores do gerencialismo no Brasil e possui uma vasta obra sobre o assunto. Bresser-Pereira (2010) reconhece a dialeticidade entre democracia, Estado social e reforma gerencial, mas mantém sempre o seu foco na importância do gerencialismo como a solução para os problemas do Estado, depois do fracasso da burocracia pelo aumento das demandas do cidadão.

Nessa lógica, a Reforma do Estado no Brasil foi considerada condição essencial para que se alcançasse o patamar dos países desenvolvidos. O autor caracteriza, assim, a administração pública gerencial como legitimadora do Estado social e neutralizadora das tendências neoliberais que visam a reduzir o Estado. Esse discurso adotado por Bresser-Pereira (2010) revela uma evolução da concepção do gerencialismo, tal qual idealizado por Margareth Thatcher, ao observar que, não necessariamente o Estado mínimo é o melhor.

Bresser-Pereira (2010) também defende um Estado pragmático, em que governar não é só garantir um regime político, mas, ainda, primar pela sua organização, no que se torna mais uma vez evidente sua forte inclinação para adotar modelos que "deram certo", visto a argumentação de que o Estado social, que se torna dominante nos países desenvolvidos após a Segunda Guerra Mundial, foi resultado da ampliação da democracia, mas sem que os governantes perdessem o controle.

Assim, encontra-se, por meio dessa breve descrição, uma situação emblemática do constructo da Teoria $\mathrm{N}$ de Guerreiro Ramos, uma vez que está claro seu enraizamento na dicotomia "nações em desenvolvimento" versus "nações desenvolvidas". Ademais, os autores dos textos defendem que existe um caminho ótimo e único para se atingir o almejado desenvolvimento, orientando-se pelo the best way, que prima o alcance da modernização nos moldes da racionalidade instrumental.

É perceptível, pela apreensão das ideias desses autores, a existência de um processo normal e unilinear de evolução, tal qual descrito por Guerreiro Ramos como pressupostos da Teoria N. Outro quesito que merece destaque, e que ajuda para essa qualificação, é o fato de que, segundo Paes de Paula (2005a), com o modelo gerencial instaurou-se uma novíssima dependência, ou seja, o Brasil continua se colocando em uma posição de país em desenvolvimento, dependente dos avanços dos países de Primeiro Mundo.

Contudo, não se alteraram características historicamente construídas em um estalar de dedos, no que Paes de Paula (2005a; 2005b) também concorda, ao estender em suas análises tópicos a respeito dos limites do gerencialismo, pois considera que não foi absorvido em sua totalidade no Brasil. Por outro lado, uma segunda implicação parece tão ou mais grave, pois está relacionada à importação de práticas de modo acrítico e acontextual, corroborando a crítica emanada da "redução sociológica" de Guerreiro Ramos. Isso significa dizer que não se buscou compreender os conteúdos nucleares da proposta gerencialista na adoção do conteúdo estrangeiro, havendo a estranha isenção de uma postura reflexiva, coadunando uma leitura superficial dos fenômenos, como criticam Bergue e Klering (2010).

Voltando aos aspectos desenvolvimentistas, encontra-se, também, em Dowbor (1999), uma ampla crítica quanto ao fato de considerar o crescimento econômico sinônimo de desenvolvimento econômico. Dowbor (1999) descreve a realidade social brasileira da década de 1990 como preocupante, visto que os resultados explicitados pela incorporação da social-democracia à vida pública não foram satisfatórios, pois houve um estancamento da redistribuição de renda, aumento do desemprego e dilapidação do meio ambiente. 
Seguindo nessa linha de pensamento, que clama por novas possibilidades, procuramos identificar e analisar os estudos que possam contribuir para elucidar a existência de uma administração pública tupiniquim, aqui considerada enquanto a formação de "possibilidades objetivas" que melhor atendam as especificidades do Brasil. A presença dessa forma de administração no Brasil justifica-se pelo fato de que o país não absorveu totalmente o gerencialismo e sequer assumiu completamente a burocracia. Assim, na prática, por esbarrar em características culturais tais como o autoritarismo e o coronelismo, a administração pública gerencial não foi plenamente desenvolvida no Brasil, sendo relativizada em sua aplicação, tornando-se uma hibridização de diversas abordagens de gestão, pois une as características do patrimonialismo, da burocracia, do gerencialismo e da gestão social (PAES DE PAULA, 2005a; 2005b). Essa hibridização institui, na verdade, um novo modelo de gerir a coisa pública, formando o que denominamos administração pública tupiniquim, uma administração pública flexibilizada, absorvendo elementos de vários modelos e experiências acumuladas ao longo da história no Brasil e no exterior.

Desse modo, ao pensarmos em uma forma de representar a administração pública tupiniquim como um tipo de administração pública que representa a realidade brasileira, pode-se compreendê-la como a integração dos principais modelos debatidos na literatura, como ilustrado na Figura 1.

Figura 1

\section{Administração pública tupiniquim}

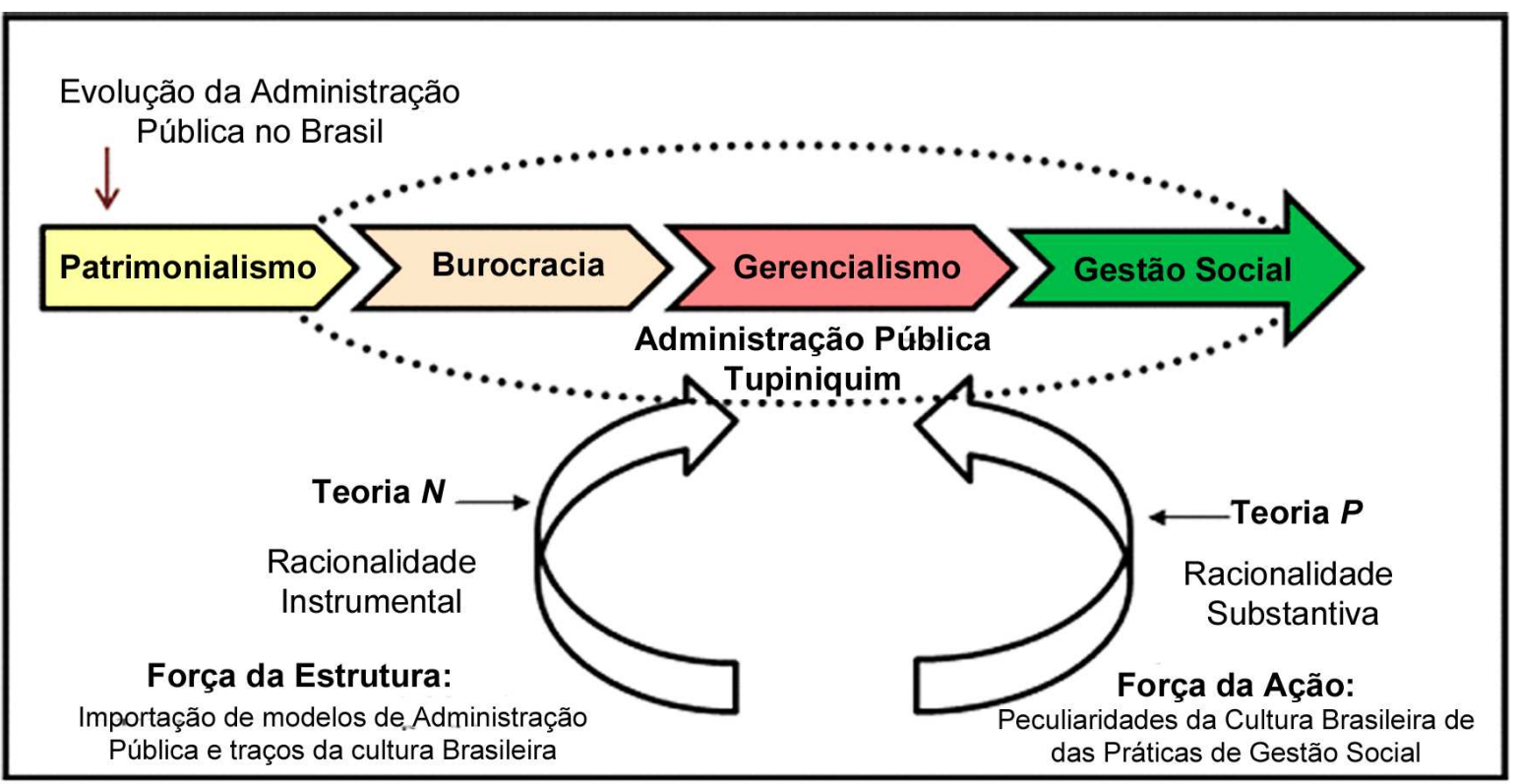

Fonte: elaborada pelos autores.

Observa-se, na Figura 1, que a administração pública tupiniquim integra, principalmente, as abordagens burocrática, gerencial e da gestão social. No entanto, tem-se uma importante ressalva quanto à presença da abordagem patrimonialista, parcialmente incluída no círculo que identifica uma administração pública genuinamente brasileira. Mesmo tendo sido combatido pelos governos desde a década de 1960, o patrimonialismo ainda não foi eliminado das práticas públicas brasileiras. Silva et al. (2010) o confirmam ao afirmar que, mesmo ferindo a Constituição Federal e legitimando atitudes e costumes advindos das relações de poder e dominação, o modelo ainda se mantém arraigado na esfera política atual, pois a dependência da máquina pública se tornou cultural, mediada pela defesa de interesses particularizados. Assim, apesar de não dever integrar o modelo da administração pública tupiniquim, quando o pensamos como um tipo ideal de 
administração a ser conquistado, na Figura 1 a abordagem patrimonialista ainda persiste para demonstrar que não pode ser ignorada a presença dessa prática cultural, permanecendo sua superação como desafio.

A administração pública tupiniquim, além de ser um modelo resultante da hibridização das abordagens de gestão originadas em diferentes momentos históricos, integra as forças sociopolíticas da estrutura e da ação, sendo a estrutura representada pela Teoria $\mathrm{N}$ e a ação representada pela Teoria $\mathrm{P}$ de Guerreiro Ramos, de modo que a sua convergência é expressa por meio das características da cultura brasileira. Dentre as peculiaridades manifestadas pela cultura brasileira, destacam-se as práticas de gestão social como promotoras da evolução da gestão pública no Brasil. Paes de Paula (2005a) esclarece que a gestão social enfatiza a elaboração de experiências de gestão focalizadas nas demandas populares, incluindo movimentos sociais, conselhos gestores de políticas públicas, orçamento participativo, dentre outras iniciativas. A autora se baseia no conceito de gestão social apresentado e desenvolvido por Tenório (1998) e propõe, então, a construção de um modelo que ela denomina "administração pública societal".

A mesma autora ressalta que a "administração pública societal" se fundamenta, principalmente, nas ações públicas dos movimentos sociais datados do inicio dos anos 1960, com desdobramentos nas três décadas posteriores. O modelo integra um projeto político que enfatiza a participação social e o repensar do enfoque dado ao desenvolvimento. A estrutura do aparelho do Estado e o paradigma de gestão, cuja dimensão enfatizada na gestão é a sociopolítica (PAES DE PAULA, 2005a).

Assim, no âmbito do Estado burocrático-gerencial, as práticas de gestão social evidenciam a existência de uma administração pública tupiniquim, correspondente à Teoria $\mathrm{P}$ de Guerreiro Ramos como uma verdadeira possibilidade objetiva, uma vez que a gestão social se traduz como uma manifestação criativa da vontade do cidadão, em meio à adequação de tecnologias importadas. Esse fato é evidenciado por Paes de Paula (2005a, p. 158), ao afirmar que na administração pública societal "o desenvolvimento é interpretado como a busca de respostas criativas para problemas que envolvem escassez de recursos e que podem ser resolvidos através do estímulo ao potencial produtivo e à participação cidadã". Desse modo, a convivência e a mescla de técnicas gerenciais típicas dos quatro modelos de gestão em um mesmo espaço e território caracterizam o que denominamos "administração pública tupiniquim". Nesse sentido, pode-se afirmar que existe uma ressignificação das impressões vindas do estrangeiro, não necessariamente baseada na apreensão crítica das necessidades do Estado e da Sociedade, mas como um dos traços da cultura brasileira de relativizar o uso de modelos importados.

Assinala-se que, quando a ressignificação dos modelos importados de administração esbarra nas peculiaridades de uma cultura nacional, tal qual no caso brasileiro, observa-se a inclinação para a miscigenação com modelos já existentes. Por outro lado, quando ocorre a transposição crítica de um modelo estrangeiro, abrem-se espaços para a criatividade na gestão pública, como se tem observado em relação à gestão social. Contudo, pode-se assegurar que a gestão social possui elementos marcantes e, por isso, é passível de uma breve análise, por estar contribuindo em grande monta para a formação de uma verdadeira "possibilidade objetiva" na administração pública brasileira.

As alternativas propostas pela abordagem da gestão social podem ser empiricamente encontradas em nível local e orientam-se, basicamente, pela racionalidade substantiva, ao primar pelo desenvolvimento social e não estritamente pelo econômico. Para compreender essa proposta, abre-se espaço ao conceito de esfera pública, de Habermas (1984), na medida em que ela é caracterizada pela participação da sociedade na discussão e nas decisões dos negócios públicos. Isso porque a gestão social como "possibilidade objetiva" de um tipo de gestão pública não estatal tem suas raízes nos movimentos sociais e envolve questões sociopolíticas, motivando a organização local de experiências e alternativas de gestão, como já foi dito. Nesse sentido, seguindo o conceito habermasiano do agir comunicativo, Tenório (1998) destaca que a gestão social contrapõe-se à gestão estratégica, uma vez que aquela prima pela dialogicidade e participação, 
envolvendo diferentes sujeitos sociais no processo decisório, enquanto esta distingue-se por uma relação monológica, pelo utilitarismo e pela competição.

São exemplos da aplicação da gestão social os conselhos gestores de políticas públicas e os orçamentos participativos. Segundo Lazzari (2010), na experiência pioneira do orçamento participativo em Porto Alegre, os movimentos sociais e as diversas ações populares e comunitárias tiveram um papel importante de organização, mobilização e reivindicação de políticas públicas no debate e decisão do orçamento público do Estado. O que se desenvolveu foi um processo de cogestão no governo, uma experiência ímpar de compartilhamento do poder com a sociedade, uma vez que se abria o orçamento do Estado para debater e decidir as receitas, as despesas e as políticas públicas com a população. No entanto, o Estado não deixou de se utilizar da burocracia e dos elementos que caracterizam o gerencialismo, seja na formalização, nos registros e no desempenho de seu papel como autoridade no processo de orçamento participativo, seja no estabelecimento de objetivos e metas a ser alcançadas, tanto pelo seu corpo de funcionários quanto pela sociedade. É nesse contexto que ganha força o sentido que queremos atribuir à "administração pública tupiniquim" enquanto resultante de múltiplos entrelaçamentos de várias abordagens ou modelos de gestão, no sentido de encontrar soluções originais e tomar decisões legítimas e democráticas. Lopes (2004) classificou essa tendência como a existência de subesferas localizadas e instituintes, em que não há uma política social como um todo, mas "políticas sociais". Portanto, confirma-se, aí, a Teoria da Possibilidade Objetiva de Guerreiro Ramos, ao caracterizarmos a administração pública brasileira contemporânea como "administração pública tupiniquim".

Portanto, o espaço que passou a ocupar a gestão da coisa pública, por meio das ONGs, das associações, da economia solidária ou do cooperativismo constitui a base para o desenvolvimento de uma administração pública genuinamente brasileira, ao estabelecer um novo padrão de relações entre sociedade, Estado e mercado, numa perspectiva de busca de equilíbrio de poder entre esses setores. Destarte, essa realidade tem sido, sobretudo, conforme Ernst Bloch, a expressão de uma utopia concreta, em que o que importa "não é diferenciar gestão pública de gestão social, mas resgatar a função básica da administração pública, que é atender aos interesses da sociedade como um todo" (TENÓRIO e SARAIVA, 2007, p. 109).

Assim, as "possibilidades objetivas" que melhor atendem a realidade brasileira partem de considerações sobre o social, o que está baseado nas proposições tanto de Guerreiro Ramos (SOARES, 2006) como de Dowbor (1999). Segundo esses autores, o desenvolvimento de fato deve considerar o social como dimensão e não como mero setor e, com isso, privilegiar a qualidade de vida em detrimento da simples maximização e soma das produtividades microeconômicas. Desse modo, a administração pública tupiniquim confirma-se enquanto tipologia da Teoria P de Guerreiro Ramos, superando a dicotomia entre mundo desenvolvido e subdesenvolvido ao considerar nossos próprios recursos e nossa própria realidade como fontes de gestão pública e como ponto de partida para construir a nação. Por outro lado, podemos chegar à conclusão de que não há espaço na realidade cultural brasileira para a predominância de um "tipo puro" de administração pública, seja ele patrimonial, burocrático, gerencial ou social. O que tende a predominar no Brasil é a hibridização desses modelos, o que consideramos de grande relevância para a gestão pública ao ressaltar os elementos positivos de cada um deles. É nesse espaço que se pode desenvolver, teoricamente, uma administração pública brasileira original, autêntica, nos moldes pensados por Guerreiro Ramos como uma possibilidade objetiva. Ao se preservar o respeito a diferentes realidades, a administração pública tupiniquim pode vir a consolidar-se no sentido de favorecer as questões nacionais, encontrando-se, nesse espaço, um dos seus maiores méritos, uma vez que essa característica fomenta sua institucionalização. Pode-se considerar que, nos últimos anos, o Brasil avançou significativamente nessa direção, pois passou a se posicionar no cenário internacional a partir de uma concepção própria de gestão pública e não de adoção acrítica de modelos alienígenas.

Assim, devemos considerar a criação de um modelo próprio, nacional, como uma alternativa que deve ser cada vez mais valorizada no pensar da administração pública, bem como na perspectiva de superação da 
nossa mentalidade "colonial", que faz persistir o patrimonialismo enquanto um dos traços negativos da cultura pública brasileira. Dessa forma, a principal vantagem de uma administração pública tupiniquim consiste na preservação e valorização dos aspectos positivos da cultura brasileira. Em outro diapasão, um dos grandes desafios a serem superados pela administração pública tupiniquim é o rompimento com traços aviltantes, tais como as disfunções burocráticas e o patrimonialismo arraigado. Além disso, outro desafio desse modelo autêntico de gerir a coisa pública é a ampliação e consolidação das práticas, que ainda são incipientes, de gestão social, tendo em vista que primam pela emancipação do indivíduo.

Com base nessas considerações, acreditamos que o desenvolvimento teórico e prático da administração pública tupiniquim se adequa a características originárias da história do Brasil, não se configurando como uma simples cópia de modelos de gestão pública estrangeiros. Como isso, reconhece-se a existência um modelo próprio de gerir a coisa pública, que recebe influências da racionalidade substantiva e da cultura brasileira, o que confirma, mais uma vez, o sentido da Teoria da Possibilidade de Alberto Guerreiro Ramos.

\section{Considerações Finais}

Para entender os fundamentos das práticas gerenciais no Brasil, este ensaio teórico partiu do resgate do contexto histórico da administração pública, por meio das obras de Osborne e Gaebler (1994) e Giddens (1999; 2001). Os primeiros relatam em sua obra como se agregaram características empreendedoras no governo dos EUA. Sob a égide do discurso do sucesso, os autores prescrevem dez passos para se atingir o almejado desenvolvimento. Em Giddens, lê-se sobre a terceira via na Inglaterra, que foi idealizada como uma conduta ideológica situada entre o socialismo e o liberalismo. Ambas as abordagens convergem na consolidação do gerencialismo.

Além disso, a importação de modelos explica-se pelo mito do desenvolvimento, que segrega as nações em "desenvolvidas" e "em desenvolvimento". Do modo como foi idealizada no Brasil, a administração pública gerencial pode ser incluída no contexto da classificação teórica de Guerreiro Ramos como Teoria N, uma vez que está permeada pela novíssima dependência e defende que existe um processo normal e unilinear de evolução. Todavia, esse modelo não foi desenvolvido tal qual havia sido desenhado, pois esbarrou em peculiaridades nacionais, tais como o forte ethos burocrático, o autoritarismo, o coronelismo e o personalismo. Dessa forma, esse modelo foi "tropicalizado", entrelaçando-se aos modelos já existentes na administração pública brasileira.

Assim, pode-se considerar que a administração pública gerencial, na prática, não é a replicação pura e simples adotada no âmbito internacional, pois o modelo sofreu adaptações aos moldes "tupiniquins", conferindo-lhe contornos próprios. Dessa forma, propõe-se que a composição encontrada no Brasil, em especial das abordagens burocrática, gerencialista e dos indícios de gestão social formam o que denominamos "administração pública tupiniquim". Nesse sentido, este ensaio teórico teve como provocação central promover uma reflexão acerca dessa administração hibridizada. Ao fazê-lo, adotou-se a abordagem das Teorias N e P de Guerreiro Ramos como enfoque metodológico, resgatando-se as características de cada uma.

A crítica efetuada a partir da leitura de Guerreiro Ramos mostrou que é preciso vencer o determinismo histórico que tem ditado as inclinações teóricas que regem a administração pública brasileira, uma vez que a realidade clama pela superação da redução epistemológica. A exemplo do que assevera Rezende (2009), a plena consciência não é aquela reduzida à apreensão formal - e pode-se dizer também "acrítica" - de leis universais, deterministas. Quando afirma que todas as sociedades estão em desenvolvimento, Guerreiro Ramos aponta para a construção de um novo paradigma, em que não existem modelos de sucesso a ser seguidos, o que remete à liberdade de construção de novas ações em detrimento das rígidas estruturas pré- 
concebidas. Em termos de Brasil, pode ser pensado que muito tempo se perdeu por se acreditar que um modelo importado de gestão pública fosse oferecer a melhor saída.

A recusa de ser formatado por verdades a priori, associada à assimilação da razão noética, que leva a pensar no singular, pode delinear novos rumos à administração pública no Brasil, a exemplo de alguns casos dispersos na realidade brasileira, os quais precisam ser expandidos e mais bem estudados. Estes se traduzem nas práticas de gestão social, com enfoque na participação cidadã e, pode-se dizer, são a "ponta de um iceberg", ainda não desvendado nem acreditado. Assim, os autores que versam a respeito da gestão social corroboram sua qualificação como adeptos da Teoria $\mathrm{P}$ de modo especial, haja vista que seu pensamento não segue a estrutura determinística consolidada pela administração pública gerencial. Diferentemente, constituise como uma alternativa, uma possibilidade, considerando o sistema de desenvolvimento da sociedade como um todo.

Espera-se que este ensaio contribua para ampliar a discussão a respeito da importância da gestão pública brasileira em incluir condutas de racionalidades que abarquem mais adequadamente suas necessidades e cultura. A ilustração sistematizadora da administração pública tupiniquim procurou contribuir para a construção de um arcabouço teórico próprio da realidade brasileira, conjugando elementos positivos da cultura e os aspectos positivos das abordagens apresentadas. Outrossim, ao valorizar a Teoria $\mathrm{P}$ de Guerreiro Ramos, procurou-se evidenciar as possibilidades de rompimento com os padrões determinísticos que se quer instaurar na administração pública brasileira.

Por fim, procurou-se fazer um alerta sobre as técnicas gerenciais e os modismos transpostos à gestão pública, que mais parecem artimanhas levadas a cabo por partidários de pretensões políticas equivocadas, a fim de que não sejam adotadas de modo mecânico, a-histórico e acontextual. Salienta-se que, no Brasil, estudos que utilizam as Teorias N e P de Guerreiro Ramos ainda são incipientes. Nesse sentido, investigações futuras podem explorar outros aspectos, utilizando como lente essas teorias propostas por Guerreiro Ramos, visto que são poderosas ferramentas analíticas dos percursos ideológicos no que se refere à estrutura e à ação. Portanto, cabe sugerir novos estudos que procurem demarcar e evidenciar as características do que denominamos administração pública tupiniquim, no sentido de avançar teoricamente em relação ao modo próprio de gestão pública brasileira.

\section{Referências}

BECK, U.; GIDDENS, A.; LASH, S. Modernização reflexiva: política, tradição e estética na ordem social moderna. São Paulo: Ed. Unesp, 1997.

BERGUE, S. T.; KLERING, L. R. A redução sociológica no processo de transposição de tecnologias gerenciais. Organizações \& Sociedade, v. 17, n. 52, p. 137-155, jan./mar. 2010.

BLOCH, E. O princípio esperança. Rio de Janeiro: Ed. UERJ/Contraponto, 2005. v. 1.

O princípio esperança. Rio de Janeiro: Ed. UERJ/Contraponto, 2006a. v. 2.

O princípio esperança. Rio de Janeiro: Ed. UERJ/Contraponto, 2006b. v. 3.

BRESSER-PEREIRA, L. C. Gestão do setor público: estratégia e estrutura para um novo Estado. In: BRESSERPEREIRA, L. C.; SPINK, P. K. (Orgs.). Reforma do Estado e administração pública gerencial. Rio de Janeiro: Ed. FGV, 2003a. p. 21-38. 
Da administração pública burocrática à gerencial. In: BRESSER-PEREIRA, L. C.; SPINK, P. K. (Orgs.). Reforma do Estado e administração pública gerencial. Rio de Janeiro: Ed. FGV, 2003b. p. 237-270.

Democracia, Estado social e reforma gerencial. Revista de Administração de Empresas, v. 50, n. 1, p. 112116, jan./mar., 2010.

2003.

; SPINK, P. K. (Orgs.). Reforma do Estado e administração pública gerencial. Rio de Janeiro: Ed. FGV,

CARDOSO, F. H. Reforma do Estado. In: BRESSER-PEREIRA, L. C.; SPINK, P. K. (Orgs.). Reforma do Estado e administração pública gerencial. Rio de Janeiro: Ed. FGV, 2003. p. 15-19.

CATALÁ, J. P. Governabilidade democrática na América Latina no final do século XX. In: BRESSER-PEREIRA, L. C.; SPINK, P. K. (Orgs.). Reforma do Estado e administração pública gerencial. Rio de Janeiro: Ed. FGV, 2003. p. 271-314.

DOWBOR, L. Gestão social e transformação da sociedade. 1999. Disponível em: <http://dowbor.org/8_gestao social.asp>. Acesso em: 22 maio 2008.

FILIPPIM, E. S.; ROSSETTO, A. M.; ROSSETTO, C. R. Abordagens da administração pública e sua relação com o desenvolvimento em um contexto regional: o caso do Meio-Oeste Catarinense. Cad. EBAPE.BR, v. 8, n. 4, p. 734-752, dez. 2010.

FREITAS JR., D. B. Avaliação da administração pública gerencial em municípios por meio de indicadores. 2009. 139p. Dissertação (Mestrado em Administração) - Universidade Federal de Lavras, Lavras (MG), 2009.

FREUND, J. Sociologia de Max Weber. 4. ed. Rio de Janeiro: Forense Universitária, 1987.

GIDDENS, A. A terceira via. Rio de Janeiro: Record, 1999.

A terceira via e seus críticos. Rio de Janeiro: Record, 2001.

GLADE, W. A complementaridade entre a reestruturação econômica e a reconstrução do Estado na América Latina. In: BRESSER-PEREIRA, L. C.; SPINK, P. K. (Orgs.). Reforma do Estado e administração pública gerencial. Rio de Janeiro: Ed. FGV, 2003. p. 123-140.

HABERMAS, J. A mudança estrutural da esfera pública: investigações quanto a uma categoria da sociedade burguesa. Rio de Janeiro: Tempo Brasileiro, 1984.

HEIDEMANN, F. G. Do sonho do progresso às políticas de desenvolvimento. In: HEIDEMANN, F. G.; SALM, J. F. (Orgs.). Políticas públicas e desenvolvimento: bases epistemológicas e modelos de análise. Brasília (DF): Ed. UnB, 2009. p. 23-39.

KETTL, D. F. A revolução global: reforma da administração do setor público. In: BRESSER-PEREIRA, L. C.; SPINK, P. K. (Orgs.). Reforma do Estado e administração pública gerencial. Rio de Janeiro: Ed. FGV, 2003. p. 75-121.

LAZZARI, I. A história do OP. Disponível em: <http://www.garibaldi.rs.gov.br /op/a-historia-do-op/>. Acesso em: 8 set. 2010.

LOPES, J. R. Terceiro setor: a organização das políticas sociais e a nova esfera pública. São Paulo em Perspectiva, v. 18 , n. 3, p. 57-66, 2004.

MISOCZKY, M. C. Sobre o centro, a crítica e a busca de liberdade na práxis acadêmica. Cad. EBAPE.BR, v. 4, n. 3, p. 1-13, out. 2006.

NASCIMENTO, C. Autogestão: economia solidária e utopia. Otra Economía, v. 2, n. 3, p. 27-40, 2008. 
OSBORNE, D.; GAEBLER, T. Reinventando o governo: como o espírito empreendedor está transformando o setor público. Brasília (DF): MH Comunicação, 1994.

PAES DE PAULA, A. P. Por uma nova gestão pública: limites e potencialidades da experiência contemporânea. Rio de Janeiro: Ed. FGV, 2005a.

Administração pública brasileira: entre o gerencialismo e a gestão social. Revista de Administração de Empresas, v. 45, n. 1, p. 36-52, jan./mar. 2005b.

PEREIRA, J. R. Reforma do Estado e administração pública em Minas Gerais: avanços e desafios. In: FERREIRA, M. A. M.; EMMENDOERFER, M. L.; GAVA, R. (Orgs.). Administração pública, gestão social e economia solidária: avanços e desafios. Viçosa (MG): Ed. UFV, 2010. p. 130-144.

PRZEWORSKI, A. Sobre o desenho do Estado: uma perspectiva agent $\times$ principal. In: BRESSER-PEREIRA, L. C.; SPINK, P. K. (Orgs.). Reforma do Estado e administração pública gerencial. Rio de Janeiro: Ed. FGV, 2003. p. 3973.

RAMOS, A. G. A nova ciência das organizações: uma reconceituação da riqueza das nações. Rio de Janeiro: Ed. FGV, 1981.

A redução sociológica. Rio de Janeiro: Ed. UFRJ, 1996.

. A modernização em nova perspectiva: em busca do modelo da possibilidade. In: HEIDEMANN, F. G.; SALM, J. F. (Orgs.). Políticas públicas e desenvolvimento: bases epistemológicas e modelos de análise. Brasília (DF): Ed. UnB, 2009.

REZENDE, U. S. Antropologia fundamental e teoria das organizações. In: HEIDEMANN, F. G.; SALM, J. F. (Orgs.). Políticas públicas e desenvolvimento: bases epistemológicas e modelos de análise. Brasília (DF): Ed. UnB, 2009.

SILVA, E. A. et al. Implicações teóricas entre administração pública, institucionalismo e capital social. In: FERREIRA, M. A. M.; EMMENDOERFER, M. L.; GAVA, R. (Orgs.). Administração pública, gestão social e economia solidária: avanços e desafios. Viçosa (MG): UFV, 2010. p. 202-222.

SOARES, L. A. A. A sociologia crítica de Guerreiro Ramos: um estudo sobre um sociólogo polêmico. Rio de Janeiro: CRA, 2006.

TENÓRIO, F. G. Gestão social: uma perspectiva conceitual. Rev. Adm. Pública, v. 32, n. 5, p. 7-23, set/out. 1998.

. ; SARAIVA, E. Escorços sobre a gestão pública e gestão social. In: MARTINS, P. E. M.; PIERANTI, O. P.

(Org). Estado e gestão pública: visões do Brasil contemporâneo. Rio de Janeiro: Ed. FGV, 2007. p. 108-132. 